\title{
El color sí importa
}

\author{
Cristina Rey Pais - Beatriz Durana Tonder - Beatriz Pereira Ogando - María del Carmen Prado Meis \\ Cándido Díaz Rodríguez
}

Unidad de Hemodiálisis. Hospital "Virxe da Xunqueira". Cee (A Coruña)

\section{Sra. Directora:}

En este texto se pretende reflejar la gran importancia que tuvo en nuestra unidad de diálisis la faceta observadora del personal de enfermería en la detección de un problema de salud en una paciente en programa de hemodiálisis periódica. Pretendemos valorar la eficacia de la observación en una unidad de diálisis como método de detección precoz y describir con datos objetivos, analíticos y diagnósticos un caso clínico.

Mujer de 74 años con insuficiencia renal crónica secundaria a nefropatía diabética, en HD desde hace 3 años, con hipertensión, diabetes tipo 2 con síndrome metabólico, bloqueo AV completo, portadora de marcapasos, bronquitis crónica y colecistitis aguda recidivante, con varios ingresos en el servicio de cirugía que evolucionaron de manera favorable con tratamiento conservador.

La paciente se dializa 3 veces a la semana 4 horas, con hemodiálisis convencional con bicarbonato. El acceso vascular es una FAVI radio-cubital; se utiliza un dializador de polisulfona de 1,8 $\mathrm{mts}$ _ con coeficiente de ultrafiltración de $75,3 \mathrm{ml} / \mathrm{hr} / \mathrm{mm} \mathrm{Hg}$ y heparinización con bemiparina 2500 UI.

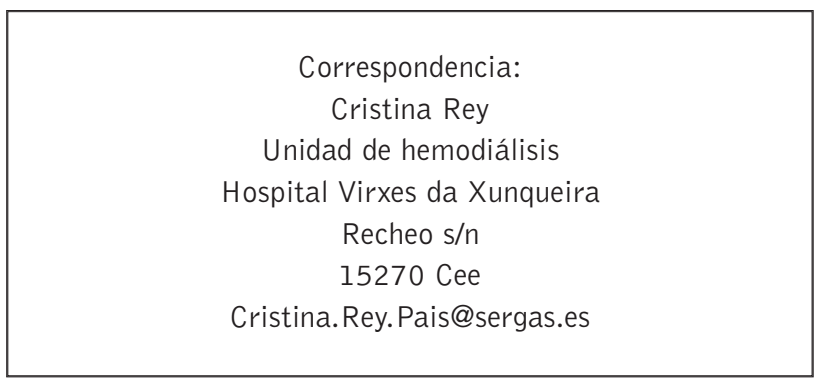

En los análisis que se realizan al inicio de cada mes a todos los pacientes que reciben tratamiento dialítico en nuestra unidad no se objetiva alteración de la bilirrubina total $(0,44 \mathrm{mgr} / \mathrm{dl})$ ni del resto de los parámetros hepáticos. Transcurridos 20 días tras la realización de la última analítica se observa al término de la sesión de HD una ligera coloración amarillenta de las fibras del dializador. En la siguiente sesión se hace analítica y se obtiene como resultado 3,86 $\mathrm{mgr} / \mathrm{dl}$ de bilirrubina y alteración del resto de parámetros hepáticos con patrón de colostasis y citolisis con elevación de transaminasas. Al finalizar la sesión de ese día la coloración amarillenta del dializador es más acentuada. Al interrogar a la paciente, ésta refiere dolor en hipocondrio derecho de aproximadamente una semana de evolución, anorexia y algún vómito ocasional. Se realiza exploración clínica en la que se aprecia: tinte ictérico, estabilidad hemodinámica, abdomen blando, depresible, no doloroso a la palpación profunda. No masas ni megalias. Ruidos hidroaéreos positivos de características normales. Murphy positivo. No signos de irritación peritoneal.

En la siguiente sesión se realiza un nuevo control analítico y una ecografía abdominal. En el resultado hay un incremento progresivo de la cifra de bilirrubina con respecto al resultado anterior. En la ecografía abdominal se demuestra la existencia de colelitiasis sin colecistitis ni dilatación de la vía biliar intra y extrahepática. Se deriva al servicio de urgencias del hospital de referencia y queda ingresada en el servicio de cirugía durante 20 días en los que se realiza tratamiento médico mediante sueroterapia y antibioterapia con buena evolución.

Ante estos hechos se ha de tener en cuenta que la bilirrubina tiene un peso molecular de 584,65 daltons 
y es insoluble en agua y, por tanto, es transportada al hígado por la albúmina. La elevación de las concentraciones de bilirrubina plasmática produce ictericia. La ictericia es una pigmentación amarilla de la piel, membranas mucosas y otros tejidos. Es evidente en la piel a partir de 3,0 mgr/dl de bilirrubinemia.

El coeficiente de aclaramiento del dializador de polisulfona disminuye a medida que aumenta el tamaño de las moléculas hasta no producirse, como ocurre con la albúmina que tiene un tamaño de 66.000 daltons. Por tanto, la bilirrubina unida a la albúmina no atraviesa el poro del dializador y, en consecuencia, si hay una elevación de la concentración plasmática de la bilirrubina, ésta va a quedar retenida en la membrana del dializador dando lugar al tono amarillo descrito antes de que sea evidente en la piel.
Por tanto, cabe destacar la importancia que tiene la vigilancia continua de las potenciales alteraciones que se presentan en una sesión de diálisis y que incluyen tanto los parámetros clínicos, la observación del paciente, el monitor y todos los aspectos circunstanciales como en este caso la coloración de las fibras del filtro. Esta actitud permite evitar situaciones de alarma y aumentar la efectividad de la unidad.

\section{Bibliografía}

1. Röckel A, Hohensatt U, .Bartel J, Klingel R, Plagge A. Permeability of a New Polysulfone, Highflux Dialyser APS-650. Int. J Artif Organs.21 (10): 1326-1332.

2. Sato $Y$, Ito K, Amemiya H, Kobayashi T, Uda S, Koiwa $F$, et al. Clinical evaluation of newly developed polysulfone membrana dialyzer (APS) in long term use. J Artif Organs 26(4):858-864. 